\title{
Política económica y desarrollo competitivo para PyMEs: Colombia y China desde un análisis sistémico
}

\author{
Leidy Lorena Piñeiro Cortes ${ }^{1}$ \\ Universidad EAN \\ Ilpineiro@universidadean.edu.co \\ Maria Carolina Moreno Salamanca² \\ Universidad EAN \\ mcmoreno@universidadean.edu.co \\ R. Simón Estrella Pantoja ${ }^{3}$ \\ Universidad EAN \\ rsimonep@gmail.com
}

DOI: https://doi.org/10.21158/01208160.n82.2017.1644

Fecha de recepción: 16 de mayo de 2016 Fecha de aprobación: 23 de marzo de 2017

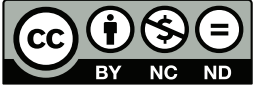

Cómo citar este artículo/ To reference this article/ Comment citer cet article/ Para citar este artigo:

Piñeiro, L.; Moreno, M. C. y Estrella, R. S. (2017). Política económica y desarrollo competitivo para pymes: Colombia y China desde un análisis sistémico Revista EAN, 82, pp.119-142. https://doi.org/10.21158/01208160.n82.2017.1644

\section{Resumen}

La revisión teórica y conceptual de la que se ocupa este artículo tiene su origen en la investigación realizada dentro de la disertación doctoral Direccionamiento estratégico para la competitividad de las pymes del sector textil-confecciones de la ciudad de Bogotá: un análisis frente a la competencia china realizada en la Universidad de Celaya en México, que a su vez se constituyó como base del proyecto de análisis y explicación de las deficiencias estructurales que impiden el desarrollo competitivo de las pymes del sector textil-confección de Bogotá frente a la competencia china desde un enfoque sistémico, desarrollado en la Universidad EAN. La variable de análisis en torno a la cual gira este texto es la política macroeconómica, razón por la cual se analiza su relación con la competitividad de las pymes del sector, la importancia de la política económica en Colombia en los dos últimos periodos presidenciales y la política económica en China en el último quinquenio.

\section{Palabras clave}

Enfoque sistémico, política económica, competitividad, PyMEs, sector textil-confecciones.

1 Doctora en Administración por la Universidad de Celaya México. Magíster en Relaciones Internacionales por la Pontifica Universidad Javeriana. Profesional en Relaciones Económicas Internacionales por la Universidad Autónoma de Colombia. Profesor Asociado, directora del Departamento de Pensamiento Económico, Entorno y Competitividad de la Facultad de Estudios en Ambientes Virtuales de la Universidad EAN.

2 Magíster en Análisis de Problemas Políticos, Económicos e Internacionales Contemporáneos por la Universidad Externado de Colombia en convenio con el Ministerio de Relaciones Exteriores el Instituto de Altos Estudios para el Desarrollo, y bajo los auspicios del Institut des HaustesEtudes de L'Amérique Latine por la Université de Paris III. Profesional en Relaciones Internacionales por la Fundación Universidad Jorge Tadeo Lozano. Profesor Asociado y Coordinadora (E) del Núcleo de Contexto y Estudios Internacionales de la Facultad de Estudios en Ambientes Virtuales de la Universidad EAN.

3 Estudiante de Negocios Internacionales. Facultad de Estudios en Ambientes Virtuales de la Universidad EAN. 


\title{
Economic Policy and Competitive Development of PyMES: Colombia and China from a Systemic Analysis Perspective
}

\begin{abstract}
This article aims at making a theoretical review based on research, which has taken place as part of a doctoral dissertation entitled Strategic Management to Achieve Competitiveness in the Textile Sector in Bogota. This research paper analyzes the impact of Chinese competition on the textile sector, which also sets the bases for a project done at Universidad EAN. This study analyzes and describes structural differences that stop competitive development of PyMEs from the textile- manufacturing sector in Bogota facing a strong Chinese competition. Its variable for the analysis made is the macroeconomic policy, a reason to study its direct relation with competitiveness of PyMes from the textile sector, the importance of the economic policy in Colombia during the last two presidential periods and the economic policy of China in the last five years.
\end{abstract}

Key words. Systemic focus, economic policy, competitiveness, PyMES, textile- manufacturing sector

\section{Politique économique et développement compétitif des PME: analyse systémique de la Colombie et de la Chine}

Resumé. L'analyse théorique et conceptuelle que nous offre cet article a pour origine la thèse doctorale "Directionnement stratégique pour la compétitivité des PME du secteur textile-confection de la ville de Bogotá: analyse face à la concurrence chinoise" réalisée par I'Université de Celaya, au Mexique, et constituant la base du projet d'analyse et d'explication des déficiences structurelles qui retardent le développement compétitif des PME du secteur textile-confection de Bogotá. La variable d'analyse prise en compte dans ce document sont la politique macroéconomique qui sera analysée sous l'angle de la compétitivité des PME du secteur et l'importance de la politique économique en Colombie lors des deux derniers mandats présidentiels ainsi que la politique économique chinoise du dernier quinquennat.

Mots clefs. Point de vue systémique, politique économique, compétitivité, PME, secteur textile confection.

\section{Política econômica e desenvolvimento competitivo para pequenas e médias empresas: Colômbia e China a partir de uma análise sistémica}

Resumo. A revisão teórica e conceitual da que se ocupa este artigo tem sua origem na pesquisa realizada dentro da tese doutoral Direcionamento estratégico para a competitividade das pequenas e médias empresas (PMEs) do setor têxtil-confecções da cidade de Bogotá: uma análise frente à concorrência chinesa, realizada na Universidade de Celaya, México, que se constituiu como base do projeto de análise e explicação das deficiências estruturais que impedem o desenvolvimento competitivo das PMEs do setor têxtil-confecção de Bogotá frente à concorrência chinesa a partir de um enfoque sistêmico, desenvolvido na Universidade EAN. A variável de análise em torno da qual gira este texto é a política macroeconômica, razão pela qual se analisa sua relação com a competitividade das PMEs do setor, a importância da política econômica na Colômbia nos dois últimos períodos presidenciais e a política econômica na China no último quinquênio.

Palabras chave. Enfoque sistêmico, política econômica, competitividade, PMEs, setor têxtil-confecções 


\section{Introducción}

as PyMEs son sujetos económicos esenciales en el desarrollo de los países. Según la Cepal (2014), las PyMEs en América Latina representan aproximadamente $99 \%$ del total de empresas, además estarían generando casi $67 \%$ de los empleos en el país. Los cambios sociales, culturales, políticos, económicos y tecnológicos de los últimos treinta años le presentan a este sector empresarial un reto importante, ya que las PyMEs deben estar preparadas para crear y mantener ventajas competitivas, agregar valor a sus productos y servicios e igualmente tener rentabilidad y sostenibilidad, pues un aspecto importante respecto de la productividad tiene que ver con la generación de diferenciación y adaptabilidad en las nuevas tendencias del mercado.

En el enfoque teórico, es importante el tema de las ventajas competitivas, por ende, las empresas deben tener planeación estratégica clara para la toma de decisiones y entornos propicios para ello. Estos procesos los deben tener todo tipo de empresas, grandes, medianas y pequeñas, ya que las decisiones de carácter estratégico son fundamentales en la prospectiva empresarial que conduzcan al fortalecimiento y mejoramiento del desempeño competitivo en su entorno nacional e internacional (David, 2003).

Con respecto a la variable de política macroeconómica, se pudo establecer con el análisis de contexto, que sin ánimo de emular modelos, es necesario que Colombia destine significativamente más recursos a mejorar la competitividad del país, que es otra tarea diferente de la de mejorar la competitividad de las PyMEs, pero que indudablemente influye y no debe ser una variable externa al modelo de competitividad, sino que deben tomarse decisiones siempre desde una perspectiva sistémica que integre en un modelo holístico los factores que influyen para hacer cada vez más competitivas las PyMEs del sector textilconfección de Bogotá y del país.

\section{Política económica de Colombia}

\subsection{Política monetaria}

En Colombia, sobre política monetaria, la meta a largo plazo está representada en el objetivo de mantener la tasa de inflación alrededor de $3 \%$, con un margen admisible de desviación de 1. En 2011, alcanzó su máximo de este quinquenio con $3.4 \%$ y su mínimo en 2013 con $2 \%$, que le ha permitido mantener una estabilidad de precios y ser considerada una economía fuerte frente a las crisis externas, mejorar la producción y mantener un crecimiento sostenido de la economía.
La principal herramienta, la tasa de interés regulada por el Banco de la República, ha permitido mantener el objetivo en la tasa de inflación. En 2010, debido a la apreciación del peso frente al dólar, pues frente al crecimiento de la economía nacional y el debilitamiento de la economía estadounidense

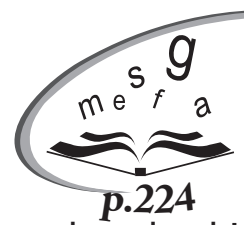
por la crisis de 2008 la moneda colombiana se apreció, el Banco de la República decidió intervenir y aumentar la compra de dólares para generar una devaluación en la moneda, medida que mantuvo hasta 2013. 
La apreciación repercutió en el aumento de las importaciones y la reducción de las exportaciones a largo plazo, que afectó varios sectores de la economía colombiana, sobre todo, al sector textil, pues hizo menos competitivo el sector y permitió el ingreso de importaciones a menor precio (Superintendencia de Sociedades, 2013) (Figura 1).

Figura 1. Tasa de interés en porcentaje anual.

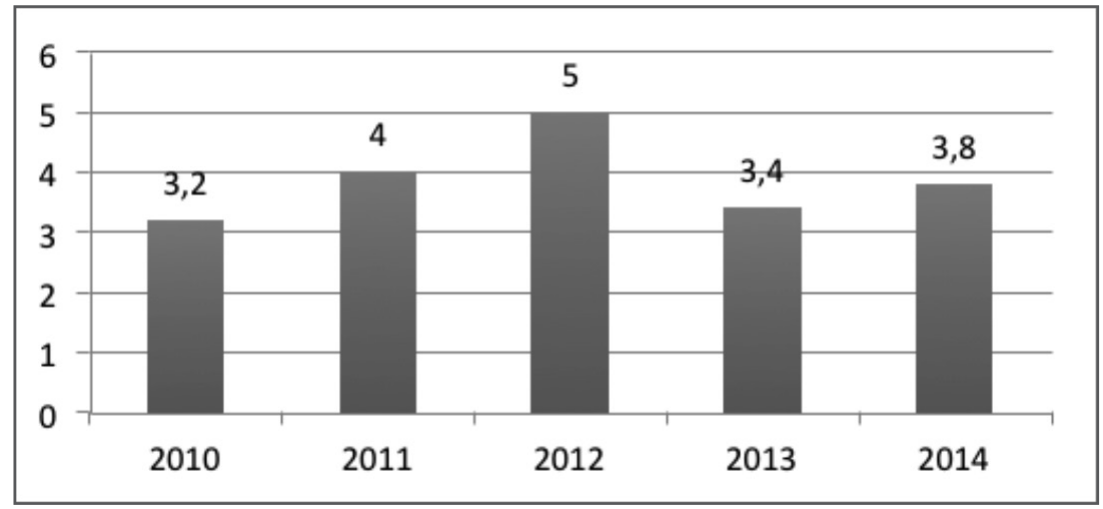

Fuente. Elaboración propia a partir de datos de la Cepal, (2014).

Apoyados en diversos estudios y partiendo de diferentes teorías y modelaciones de escenarios, en Colombia, la inflación es controlada y dirigida por los miembros de la Junta Directiva del Banco de la República que garantizan bajas tasas de inflación. En los últimos años, pese al aumento en la tasa porcentual de salarios, se ha logrado por medio de las tasas de interés mantener una inflación controlada de un dígito, lo cual ha ayudado a que Colombia sea considerada una economía fuerte frente a las crisis económicas externas, como la de 2008. En 2013, la inflación tocó su mínimo punto alcanzando $2 \%$ (-1 punto del ideal) por la intervención del gobierno, choques transitorios, precios regulados y de alimentos y ralentización del crecimiento, que ordenó tomar medidas para lograr un crecimiento en la economía de acuerdo con lo esperado.
Durante todo aquel año se observó que el Banco de la República mantuvo tasas de interés bajas, a diferencia de 2012 y 2014. En el informe de la OCDE (2015) para Colombia evalúa la economía y reconoce la estabilización de la inflación alrededor del punto objetivo y lo presenta como fortaleza para el crecimiento competitivo (Figura 2).

El índice de precios al consumidor ha sido fluctuante, solo en 2012 y 2013 ha tenido valores inferiores a 2.5 , mientras que en 2010, 2011 y 2014 su valor supera los tres puntos. La tendencia alcista en estos últimos cinco años está liderada por educación y seguida de salud, comunicaciones y viviendas. En los que menos variación han sufrido, se destaca esparcimiento, seguido de vestuario y transporte, que se mantienen bajos (Figura 3). 
Figura 2. Porcentaje de inflación.

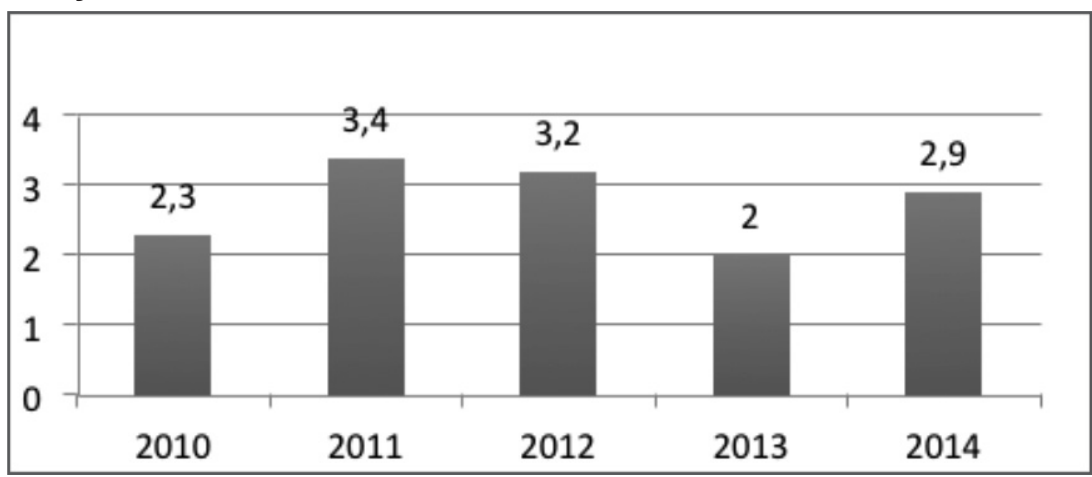

Fuente. Elaboración propia a partir de datos del Banco Mundial, (2015).

Figura 3. Índice de precios al consumidor (variación porcentual).

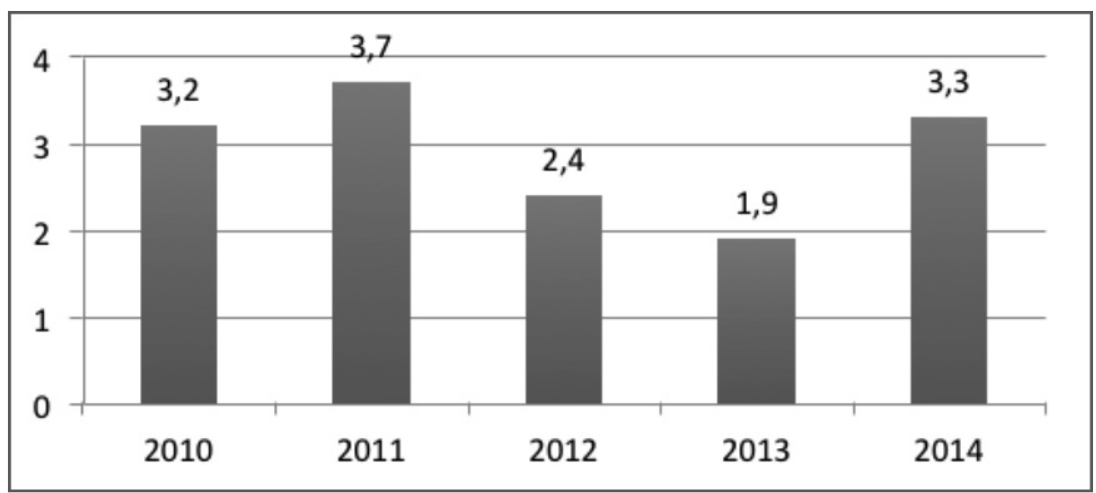

Fuente. Elaboración propia a partir de datos de la Cepal, (2015).

\subsection{Política comercial}

\subsubsection{Importaciones}

Colombia es un país altamente importador y el Gobierno ha contribuido a que ello así sea. En la reforma estructural arancelaria iniciada en 2007, y puesta en marcha en 2010, se estimulan las importaciones con la reducción del porcentaje arancelario en más

p.224 de 4000 partidas arancelarias, caso contrario a lo que ha ocurrido con los ejemplos de economías que se han fortalecido y logrado un importante avance en las exportaciones, como Taiwán, China y Corea.
Se puede observar que en 2011 las importaciones dan un salto importante, marcadas por la apreciación de la moneda, pues son más competitivos los mercados extranjeros cuyas transacciones se hacen en dólares y por las que hay que pagar menos pesos colombianos. Esto posiciona los mercados chino y europeo, que logran importantes avances en la escala de proveedores internacionales de Colombia. El crecimiento es explicado por el Gobierno como una reacción natural al crecimiento de la economía, pues demanda mayores materias e insumos para la producción, pero es de anotar que el efecto esperado para la balanza de pagos debería repercutir también en las exportaciones, lo cual ha sido mal logrado (Figura 4). 
Figura 4. Importaciones en porcentaje del PIB.

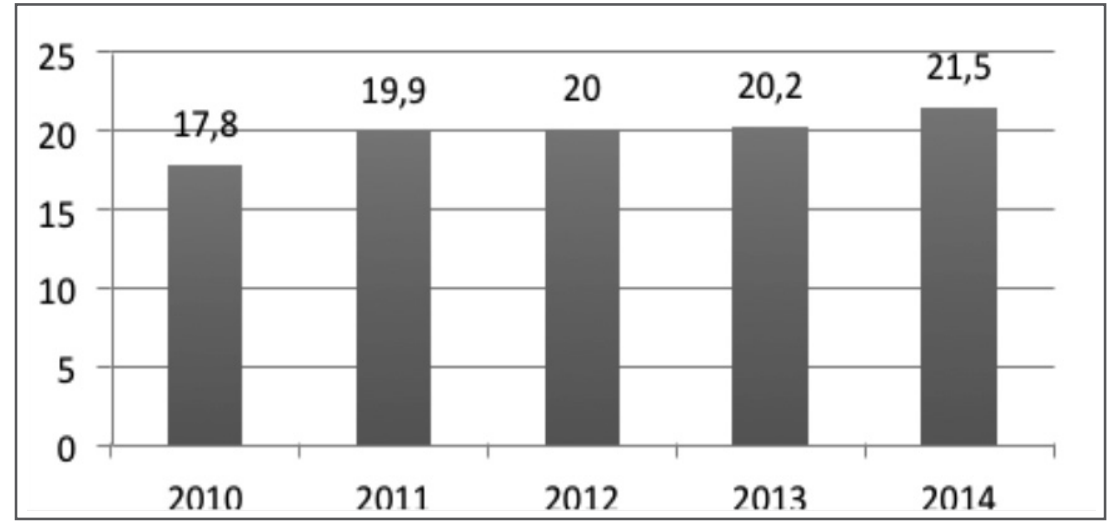

Fuente. Elaboración propia a partir datos del Banco Mundial, (2015).

Los principales proveedores son los oficina de Procolombia en Shanghái y por Estados Unidos; China, a partir de 2012, se las negociaciones para llegar a acuerdos ubica como el segundo proveedor y la Unión comerciales. En cuanto a la Unión Europea, Europea gana terreno también. El caso de el tratado de libre comercio (TLC) que entró China se explica por la arremetida en política en vigencia en 2013 marca el aumento de las exterior que puso en marcha el Gobierno de transacciones comerciales (Figura 5). Juan Manuel Santos que abrió consulado y

Figura 5. Principales diez países proveedores de importaciones.

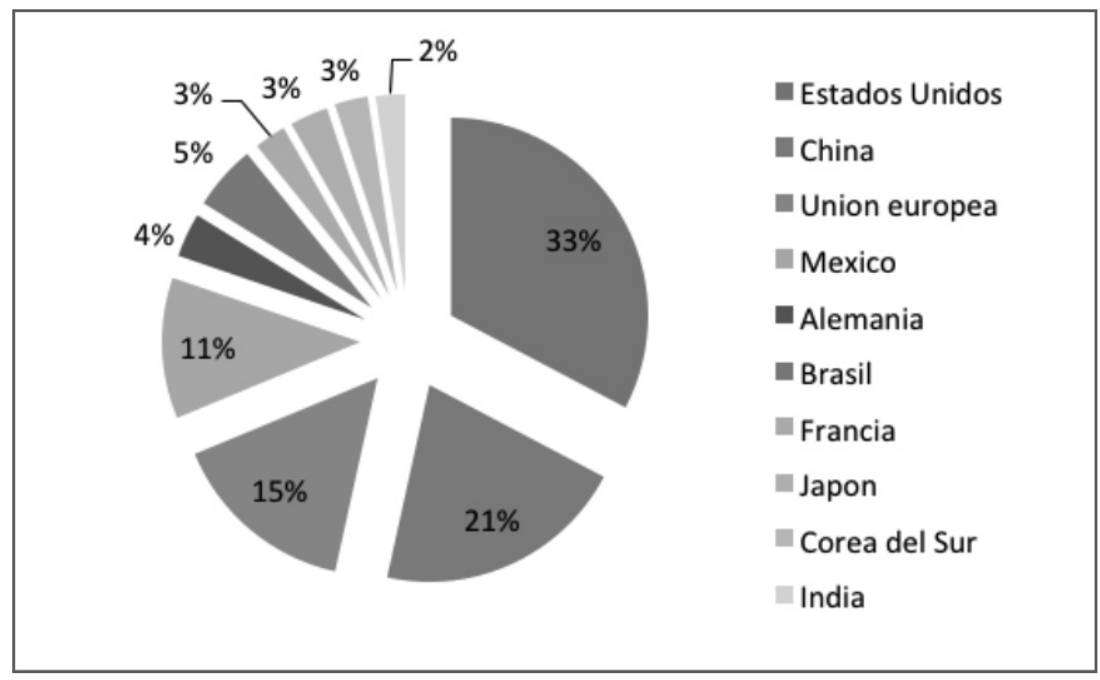

Fuente. Elaboración propia a partir de datos de MinCIT, (2015). 


\subsubsection{Exportaciones}

Colombia tiene un rezago en las exportaciones que debe mejorar para beneficiarse del comercio global y carece realmente de una política fuerte que, por lo menos, esté pensada en mejorar el nivel de exportaciones a largo plazo; en su defecto, se han destinado pequeños planes mediáticos que resuelven situaciones en auge o de momento, como el caso del alza en la demanda de materias primas. La tendencia sigue siendo a ser exportador de commodities que exponen el mercado internacional a la volatilidad. Las negociaciones de TLC en el último periodo del Gobierno de Álvaro Uribe Vélez y en el primero de Juan Manuel Santos, que bien intencionados se cerraron, han mostrado en la realidad que están lejos de aumentar las exportaciones, como resultado, en el caso del TLC con los Estados Unidos, ha dejado una balanza comercial con mayor déficit.

En cuanto al comportamiento, en 2011, se puede apreciar un salto importante marcado por la demanda de petróleo en el mercado internacional y por el crecimiento económico del país; sin embargo, tras subir tres puntos porcentuales inicia un descenso leve que ha llevado a perder lo ganado y que se explica por la desaceleración de la economía china, los síntomas de debilidad en la economía interna y por el fin de la bonanza en la demanda de materias primas en el mercado internacional. La fuerza en la demanda interna ha hecho que sectores como el de textil confección destinen parte de su producción a suplir esa demanda interna y a enfocarse en arrebatarle el mercado ganado por la competencia internacional (Figura 6).

Figura 6. Exportaciones en porcentaje del PIB.

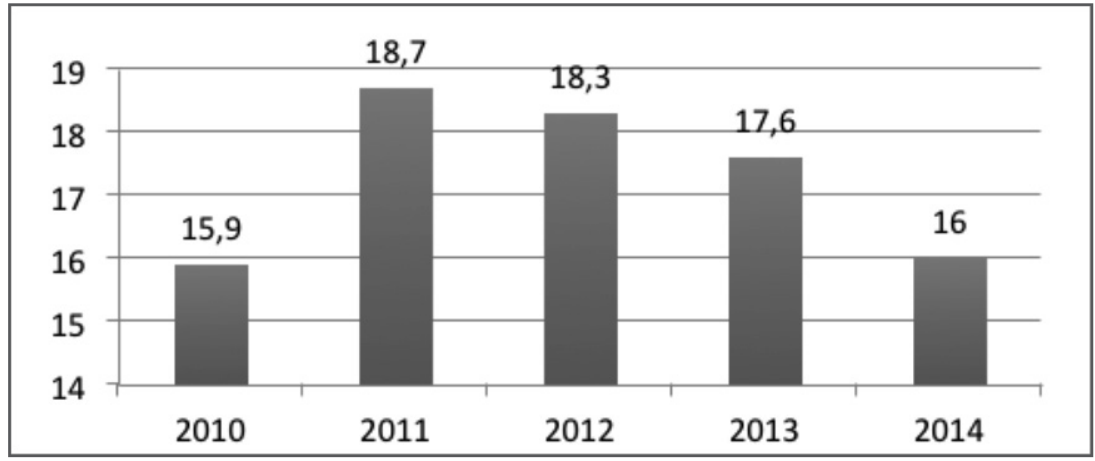

Fuente. Elaboración propia a partir de datos del Banco Mundial, (2015).

Su principal socio comercial en exportaciones sigue siendo los Estados Unidos. La Unión Europea se posiciona en segundo lugar gracias a un importante crecimiento en la demanda favorecido por el TLC que permite el ingreso de productos con arancel cero. China se ubica en tercer lugar por la demanda de petróleo, desechos de cobre, cueros, desperdicios de aluminio y carbón.
Panamá registra también un importante crecimiento por la demanda de petróleo que constituye más de $70 \%$ del comercio. Venezuela queda lejos de ser el segundo socio comercial en el mercado natural que se truncó con la compleja situación diplomática de 2008, y se ubica sexto, en parte por la demanda de alimentos que ha generado la situación de dicho país; caso contrario, la relación comercial sería menor (Figura 7). 
Figura 7. Principales diez países a los que exporta Colombia.

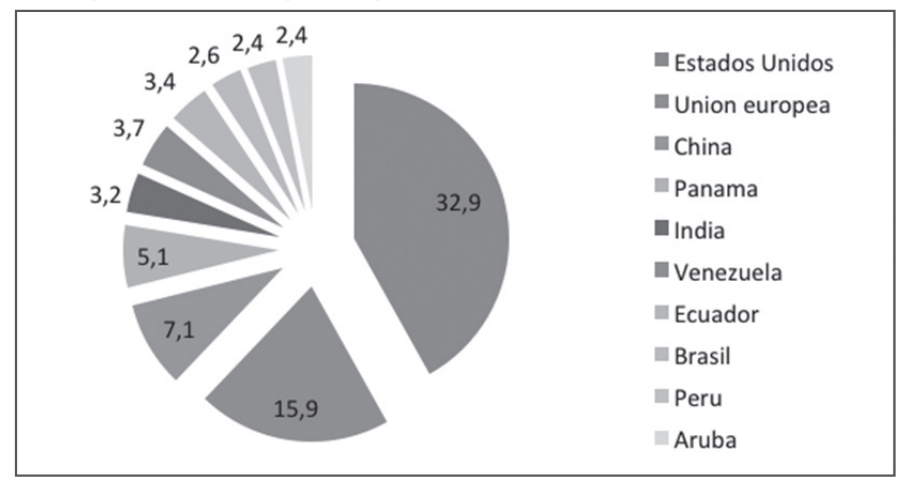

Fuente. Elaboración propia a partir del MinCIT, (2015).

\subsubsection{Balanza de pagos}

La balanza de pagos se presenta con déficit para países como China, que encabeza la lista, seguida de México, Mercado Común del Sur y Japón. La sólida demanda interna, la debilidad en las exportaciones y el bajo precio del petróleo y del carbón han hecho que la balanza de pagos y la cuenta corriente se vean afectadas drásticamente. Saldo de cuenta corriente en millones de dólares a precios actuales (Figura 8; Figura 9).

Figura 8. Saldo de cuenta corriente en millones de USD a precios actuales.

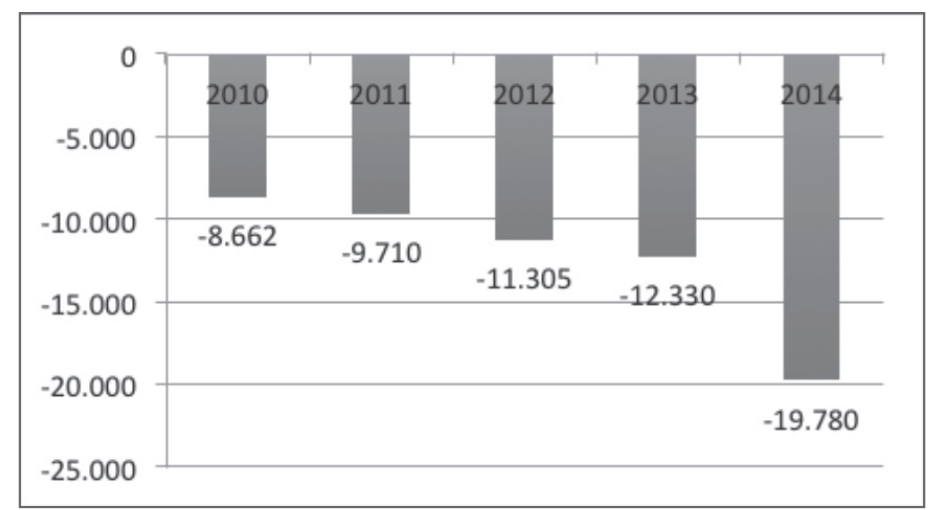

Fuente. Elaboración propia a partir de datos del Banco Mundial, (2015).

Figura 9. Balanza de pagos en millones de dólares.

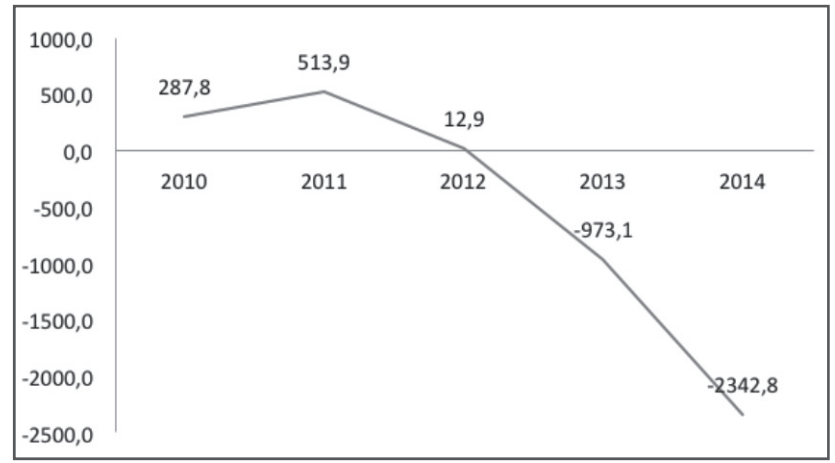

Fuente. Elaboración propia a partir de datos del Banco de la República, (2010-2014). 
En cuanto a la balanza comercial del sector textil-confección, se encuentra que las importaciones tienen un aumento brusco a partir de 2010 hasta 2012, con el débil crecimiento de las exportaciones que bajan abruptamente en 2013, pasando de una balanza comercial con superávit a déficit. Las razones, entre otras, están dadas por el cambio de arancel para materias primas en las importaciones, el crecimiento de la demanda interna no satisfecha por la producción nacional y la depreciación de la moneda a partir de la crisis económica de 2008 que abarató las importaciones y bajó la competitividad desestimulando las exportaciones. Esta situación fue motivo para imponer la medida de protección al sector en medidas arancelarias (Figura 10).

Figura 10. Comportamiento de importaciones y exportaciones textil-confección.

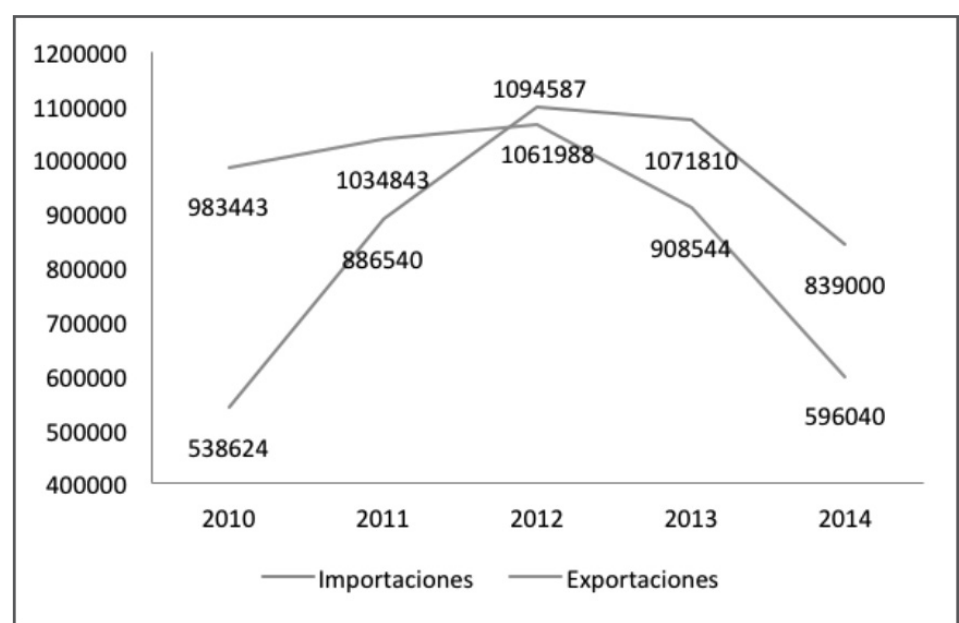

Fuente. Elaboración propia a partir de datos de la DIAN, (2015).

\subsubsection{Contrabando}

En Colombia, el contrabando técnico medido con la técnica espejo, es decir, por las importaciones que se registran por país contra las exportaciones registradas en ese país (DIAN, s.f.), proviene de los Estados Unidos alrededor de $30 \%$ en los últimos cinco años, seguido de China con cerca de $14 \%$ y México con aproximadamente 12 $\%$. En lo que se refiere a las incautaciones de contrabando (DIAN, s.f.), oscilan entre COP 70000 millones y COP 80000 millones, especialmente en la industria textil-confección que representa $49 \%$ del total (Figura 11). 
Figura 11. Contrabando.

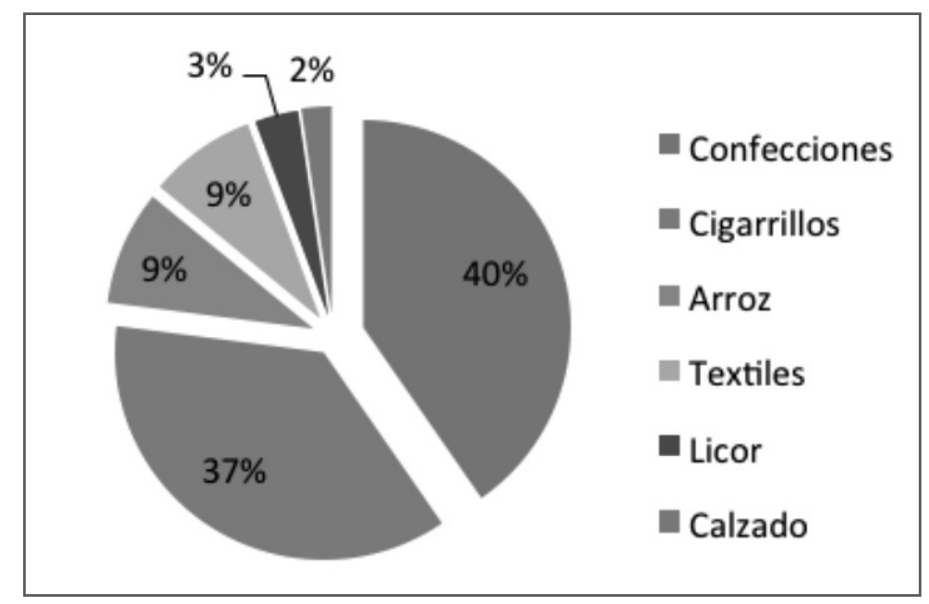

Fuente. Elaboración propia a partir de datos de la DIAN, (s.f).

Según la Superintendencia de Sociedades (2013), el contrabando es uno de los problemas que más aqueja al sector y sugiere, citando al Textile Market Watch Report, que el contrabando técnico es una herramienta utilizada en este sector por el narcotráfico para el lavado de dólares.

Tener una política anticontrabando fuerte es una necesidad para mejorar la competitividad que reviste gran importancia, pues desestimula las importaciones por contrabando clandestino y técnico y así permite al mercado ajustar precios de acuerdo con la realidad comercial, maximizar la rentabilidad en el sector y aumentar las ventas supliendo la demanda interna.

El contrabando significa dos puntos del PIB y $10 \%$ de las importaciones (OCDE, 2015); por ello, en 2013, el Gobierno presentó la Ley Anticontrabando que fue aprobada en junio de 2015 y está pendiente de sanción presidencial para que se convierta en ley de la República. Con ella, se pretende aumentar las sanciones en algunos casos de hasta $50 \%$ para el delito del contrabando, endurecer las sanciones para los funcionarios que ayuden al contrabando, fortalecer las entidades como la DIAN, la Unidad de Información y Análisis Financiero y la Policía Fiscal y Aduanera que luchan contra esta infracción y considerar a los transportistas y vendedores como partícipes de este delito.

\subsubsection{Aranceles}

En 2007, el Gobierno emprendió una reforma estructural arancelaria en busca, entre otros, de bajar el costo de importados en materias primas e insumos y bienes de capital utilizados para la producción, aumentar la competencia en los sectores recomendados por la OCDE (2015) y proteger sectores sensibles para la economía. Esta reforma, que entró en vigencia en 2010, propuso cambios en promedios para tres grandes grupos, así: bienes de capital de $9.5 \%$ a $5.3 \%$, materias primas de $10.1 \%$ a $5.4 \%$ y bienes de consumo de $19.1 \%$ a $15.7 \%$ (Díaz-Granados, 2011). Este cambio buscaba aumentar la competitividad para exportar y mejorar la producción y permitir a pequeñas y medianas industrias acceder tanto a equipos como a insumos más baratos, sobre todo, los que no se fabrican en el país. 
En 2013, y con vigencia de un año, se puso en marcha la medida de arancel adicional para el sector de textil-confección en busca de proteger el mercado de precios subfacturados, especialmente provenientes de China y Panamá. La medida implementada por el Gobierno establece un arancel compuesto de $10 \%$ ad valorem y de USD 5 por kilogramo bruto para las partidas de los capítulos 61,62 y 63 e igualmente para la partida 6406. Al finalizar el periodo de vigencia establecido para este decreto, el Gobierno reguló nuevamente la materia, ahora aplicando diferencia entre mercancía con precios inferiores a USD 10 que deberán pagar USD 5 por kilogramo adicionales a $10 \%$ ad valorem y los que tengan precio superior deberán pagar USD 3 por kilogramo. Este es uno de los pocos sectores protegidos por medidas especiales de arancel en Colombia.

\subsection{Política fiscal}

\subsubsection{Impuestos}

Aunque la tendencia a bajar los impuestos a la industria con el fin de atraer la inversión extranjera ha sido sostenida en este quienquenio, aún continúa siendo alta en comparación con otros países como China, cuya diferencia es de más de diez puntos, o México con el que la diferencia es de más de veinte puntos. Colombia se ubica en el puesto 177 de los 187 países de los que tiene información el Banco Mundial (s. f.), a diez puestos de tener la tasa más alta que es superada apenas por países como Argentina, Bolivia, República del Congo, Guinea, entre otros. Esta característica radica en los diferentes tipos de tasas impuestas a las empresas, a saber: el impuesto a la renta, el IVA, el impuesto al patrimonio neto y recientemente el CREE -impuesto sobre la renta para la equidad-, que es elevado en comparación, incluso, con la región. Como consecuencia de esto, esta tendencia resulta compleja dada su diferencia para declarar los impuestos y ha ausentado la inversión extranjera y nacional en sectores diferentes del minero energético. En este quinquenio, por recomendación del FMI (2014), se amplió la recaudación para personas naturales e impuso mayores medidas fiscalizadoras para evitar la evasión de impuestos, pues también le recomendó «hacer grandes esfuerzos para aumentar los ingresos fiscales no petroleros».

La evasión de impuesto sobre el IVA ronda $2 \%$ del PIB (OCDE, 2015), mientras que para el FMI está sobre $4 \%$ (Steiner y Medellín, 2014), lo cual está desengranado, principalmente, por el poco control sobre los contribuyentes ante la falta de personal, tecnologías de la información y de la comunicación y la flexibilidad en las sanciones. En Colombia, solo se inspecciona $0.1 \%$ de los contribuyentes, a diferencia de los otros países latinoamericanos donde el valor sube a $3 \%(O C D E, 2015)$.

La alta tasa tributaria repercute bajando la rentabilidad de las empresas y disminuyendo la competitividad, además aumenta el contrabando y la evasión de impuestos. En el sector textil, es importante tener una baja tasa que permita competir con los precios de países como China, México y la India, donde las tasas tributarias bajas incentivan las exportaciones y permiten mejores precios en el mercado internacional. La complejidad de los múltiples impuestos genera confusión en los pequeños empresarios, quienes, en muchos casos, ajenos a la realidad fiscal, dejan de pagar impuestos por desconocimiento, lo cual desencadena sanciones, poco favorables para las pequeñas empresas. 


\subsection{Las políticas de competiti- vidad en Colombia}

La competitividad es un tema casi obligado en las políticas económicas que diseña un gobierno, pues se ha convertido en un dogma considerado factor necesario para generar desarrollo en las diferentes economías, es decir, se partedel supuesto deque, cuanto más competitivo es un país, este ofrecerá mejores condiciones de vida a la población, mejor desempeño empresarial, contribuye al buen gobierno y la gestión pública y, en general, ayuda a mejorar su estructura económica y social (García, Rivas y Pavón, 2008). En el caso colombiano, la competitividad ha pasado por diversos aspectos, pues cada plan nacional de desarrollo se enfrenta a la tarea de diseñar lo que en cuatro años jalonará, según el dogma, el desarrollo del país.

\subsubsection{Plan Nacional de Desarrollo 2006- 2010 (Álvaro Uribe Vélez)}

En el Plan Nacional de Desarrollo 2006-2010 bajo el Gobierno de Álvaro Uribe Vélez, aunque la competitividad no era el plato fuerte, el capítulo 4 "Crecimiento alto y sostenido: la condición para un desarrollo con equidad" trazaba la política de desarrollo empresarial que, para resumir, estaba contenido en cinco líneas estratégicas, de las cuales tres estaban encaminadas a la competitividad así: fomento de la innovación y el desarrollo tecnológico para la competitividad, competitividad asociada con la productividad empresarial y estrategias específicas de productividad y competitividad para microempresas y pymes. El primer punto, la información trabajada por Contraloría de la Nación, fue completamente destinada al sector agropecuario. Los dos siguientes no fueron de mayor relevancia para el Gobierno, de forma tal que en los informes que entregó al Congreso de la República se limita su reseña a dos líneas breves.

Este gobierno se preocupó en por el principal sector de la producción nacional (agropecuario), y es necesario que así sea; sin embargo, pronto pasará la buena hora que vive la economía colombiana por la alza en los costos de materia prima y se volverá a estancar y seguiremos vendiéndoles al mundo productos sin valor agregado, que es el plus que necesita la producción nacional para aumentar su PIB y generar desarrollo sustentable.

\subsubsection{Plan Nacional de Desarrollo 2011- 2014 -Juan Manuel Santos-}

Con la llegada de Juan Manuel Santos a la Presidencia, el Plan Nacional de Desarrollo 2011-2014 dedica el capítulo 3, llamado "Crecimiento sostenible y competitividad», a la competitividad, en el cual resalta dos puntos: i) aumento de la productividad y ii) atracción de la inversión. El capítulo consta de seis líneas, a saber: a) innovación, tecnologías y emprendimiento; b) formalización y desarrollo de competencias; c) infraestructura para la competitividad; d) bancarización y mercado de capitales; e) clima de negocios; y f) participación privada.

Como punto clave por destacar está el reconocimiento de la informalidad como un problema en la economía visto desde la productividad. Por ello, registra la importancia de la formalización de las empresas para aumentar la productividad, pues se considera que en la informalidad se desaprovecha la capacidad de producción. 
A pesar de las buenas intenciones del Gobierno por enfocar la competitividad al aumento de la producción, el sector textilconfección no es materia de profundidad y se deja de lado sin tener en cuenta las recomendaciones contenidas en los informes consultados y hechos para el diseño del Plan Nacional de Desarrollo. En este caso, el sector se nombra solo dos veces en este capítulo y lo hace para mencionar los sectores incluidos en la política de producción, pero el sector no es objeto de una línea o política específica.

En la ejecución, sin embargo, el MinCIT generó proyectos enfocados solo a este sector, aspectos que, a pesar de las buenas intenciones, no parecen generar los mejores resultados 0 al menos no los esperados. En este orden de ideas, en 2012, se dio el mayor anuncio para el sector, con cuatro medidas que se implementarían posteriormente: i) protección por medio de aranceles, ii) lucha contra el contrabando y fraude aduanero, iii) formalización del sector -Plan Padrino-; y iv) fortalecimiento del mercado interno.

La primera medida busca proteger el sector de las importaciones subfacturadas o precios bajos y así evitar que los precios de los productos se ofrezcan en el mercado a precios que afecten la producción nacional. La segunda medida busca evitar el ingreso de mercancías ilegales al país conformando un equipo de nueve fiscales que se encargarán de investigar y judicializar los responsables de este delito. La tercera y la cuarta están enfocadas a incentivar el ingreso de las empresas a la formalidad y a fomentar el consumo de marcas colombianas, pues con eso "ganamos todos los colombianos» (MinCIT, 2012).

En 2013, se inició la ejecución de las medidas anunciadas, sin embargo, el Gobierno encontró algunos contratiempos y desarrolló también nuevas líneas. En los contratiempos, está la lentitud del proyecto de ley que buscaba fortalecer la lucha contra el contrabando, pues, desde septiembre de 2013 hasta mayo de 2015, se dieron solo dos debates. Pese a estos contratiempos, el Gobierno pidió acelerar su trámite y fue aprobado en agosto y pasó a sanción presidencial. Entre los nuevos anuncios, están el desarrollo del capital humano y la creación de una línea de crédito de Bancoldex específica para la compra de maquinaria a los empresarios del sector que hagan parte del Plan Padrino. 


\section{Política económica de China}

\subsection{Política monetaria}

En el Plan Quinquenal aprobado en 2011, China estableció medidas para controlar la política monetaria a través del Banco

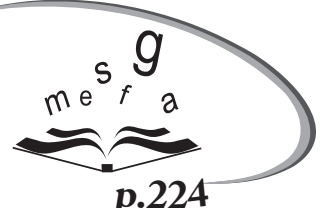

Central, igualmente frente al déficit fiscal, encaminado a reducirlo, a pesar de su paquete de intervención para recuperar la economía, que incluye gasto en infraestructuras, mejores condiciones de financiación y subsidios al consumo, que repercutió sobre los índices de precios y que posteriormente debió intervenir.

Las tasas de interés registraron alzas, toda vez que el Banco Central de China, debido a su política monetaria restrictiva, se centró en controlar las tasas de inflación registradas a causa, en parte, de las alzas en los productos extranjeros como el acero y en lo interno respecto del aumento en los salarios y la liquidez del mercado nacional. En 2011, tocó techo el IPC y en 2012 la política monetaria cambió para tornarse expansiva; sin embargo, $2 \%$ en 2014 se alejó 2 puntos de $4 \%$ fijado como meta por el Gobierno, en parte debido a la baja en los precios de los alimentos.
A pesar de que China, por su nivel como exportador y con el fin de mejorar su calidad competitiva frente a los otros mercados, mantenía una política de depreciación de la moneda frente al dólar para mantener importaciones reducidas y generar mayores exportaciones, en 2010, anunció una reforma gradual para dotar al yuan de mayor flexibilidad bajo la presión de la comunidad internacional, que exigía apreciación de su moneda. En 2012, aumentó la banda flotante frente al dólar y esto generó la mayor depreciación desde 2005 que alcanzó $-1.1 \%$, aunque en términos efectivos se ha apreciado debido a la solidez que representa la economía estadounidense.

Por la política monetaria restrictiva impartida por el Gobierno, las tasas de interés en 2010 subieron cinco veces durante seis meses para controlar el disparado IPC; sin embargo, en 2012, se avanzó en la liberación de las tasas de interés ampliando el margen para que los bancos puedan fijar sus tasas debido a la estabilización en los precios logrados por las medidas.

Después, con la política monetaria expansiva, redujo las tasas de interés paulatinamente $y$ en ocasiones de forma inesperada, con el fin de recuperar la economía (Figura 12). 
Figura 12. Porcentaje anual de inflación.

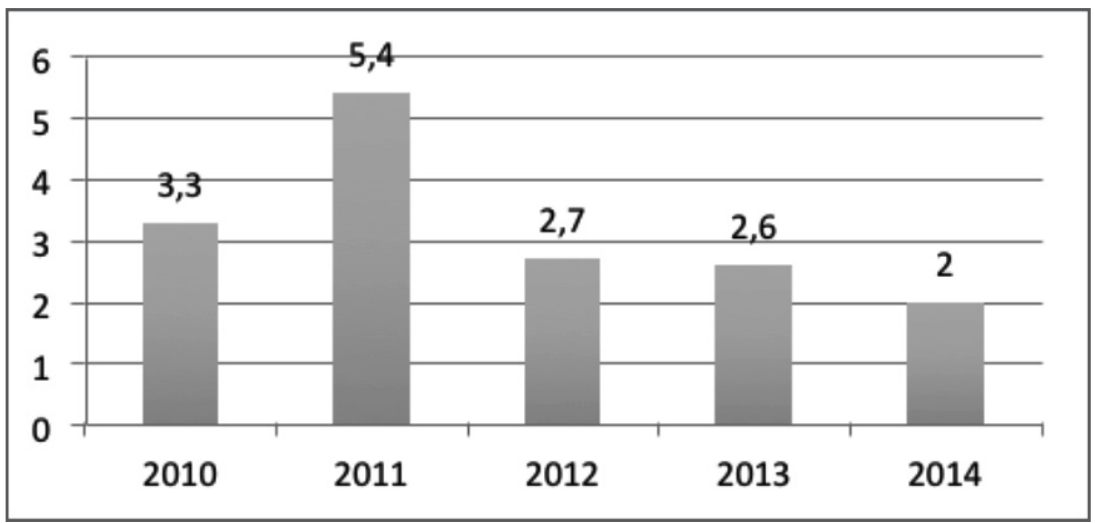

Fuente. Elaboración propia a partir de datos del Banco Mundial, (2015).

\subsection{Política comercial}

\subsubsection{Importaciones}

Sus medidas arancelarias y paraarancelarias altas permitieron mantener bajas las importaciones chinas que mejoraron hasta puntos admirables la balanza comercial con superávit. Frente a la presión internacional por la apertura de mercado que les permita en igualdad de condiciones suplir la demanda del mercado chino, el Gobierno ha tenido que flexibilizar durante este quinquenio sus medidas para el comercio exterior; sin embargo, las importaciones, lejos de aumentar, han disminuido, en parte por la revaluación de la moneda y en parte por las políticas que ha implementado el Gobierno para que las empresas chinas sean las proveedores de su propia demanda.

Principalmente, importa aceites crudos de petróleo o mineral bituminoso, circuitos electrónicos integrados, mineral de hierro y sus concentrados, automóviles para transporte de personas, dispositivos de cristal líquido, habas, gas e hidrocarburos gaseosos, piedras preciosas, partes de automóviles, aeronaves, cobre -refinado, en bruto y aleaciones-, diodos, transmisores y dispositivos semiconductores, minerales de cobre y sus concentrados, entre otros (Figura 13).

Figura 13. Importaciones en porcentaje del PIB.

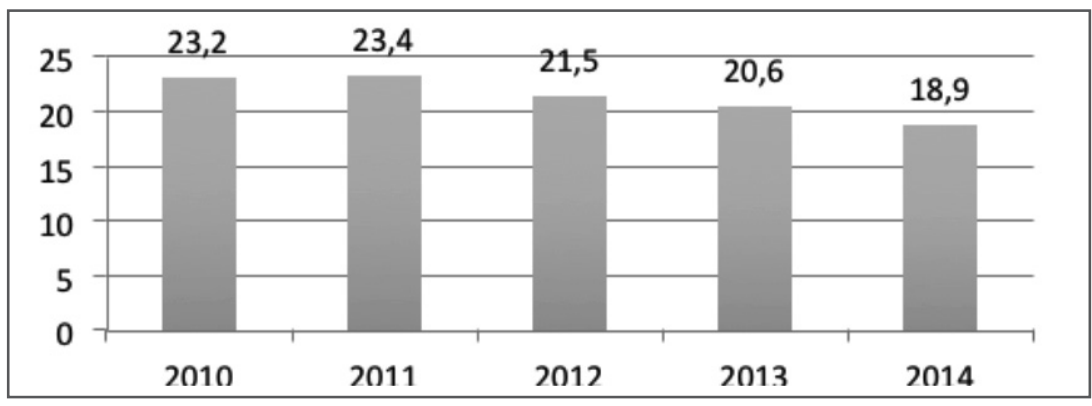

Fuente. Elaboración propia a partir de datos del Banco Mundial, (2015).

Sus exportaciones provienen básicamente de la República de Corea, Japón, los
Estados Unidos, Taiwán, reimportaciones chinas y de Alemania (Figura 14). 
Figura 14. Principales diez países proveedores de importaciones.

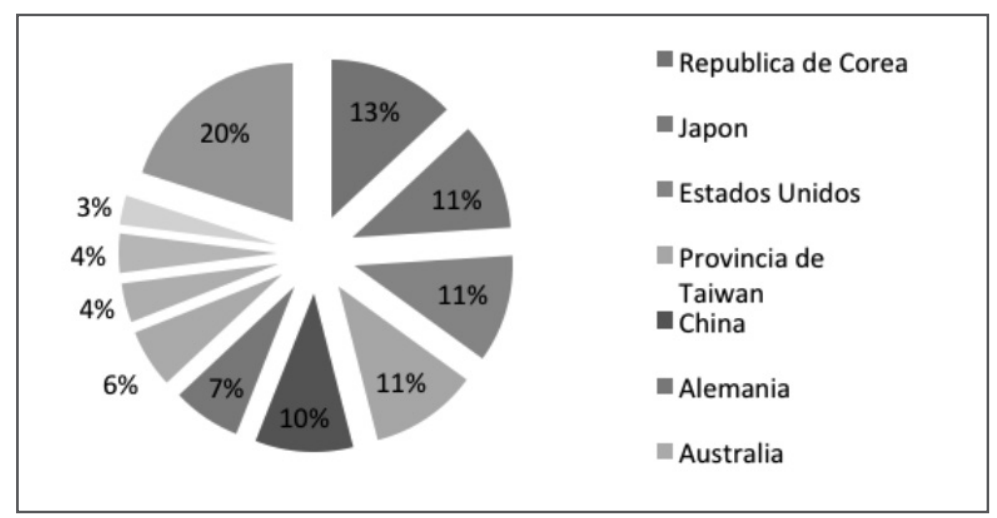

Fuente. Elaboración propia a partir de datos de Mofcom, (2015).

\subsubsection{Exportaciones}

China es potencialmente exportadora, es el primer proveedor del mundo si se toman las cifras en valores. Fue una política de los planes quinquenales anteriores y se mantiene en el vigente. Aunque los anteriores planes consideraban mantener una baja tasa salarial que ponía en desventaja a los demás países y que volvía la economía china más productiva dado su número de personas en etapa productiva y la baja demanda interna, convirtieron a China en el exportador de talla mundial que es actualmente. En este quinquenio, las exportaciones muestran una tendencia a la reducción si es vista en el porcentaje del PIB que representa, pues en 2010 significaba $26.5 \%$ y en 2014 significó solo $22.6 \%$, lo cual se explica por factores como la desaceleración económica, la apreciación del yuan y, en cierta forma, por su política enfocada a aumentar el consumo interno a partir del último plan quinquenal con el aumento en la tasa salarial y grandes planes de inversión en infraestructura (Figura 15).

Figura 15. Exportaciones en porcentaje del PIB.

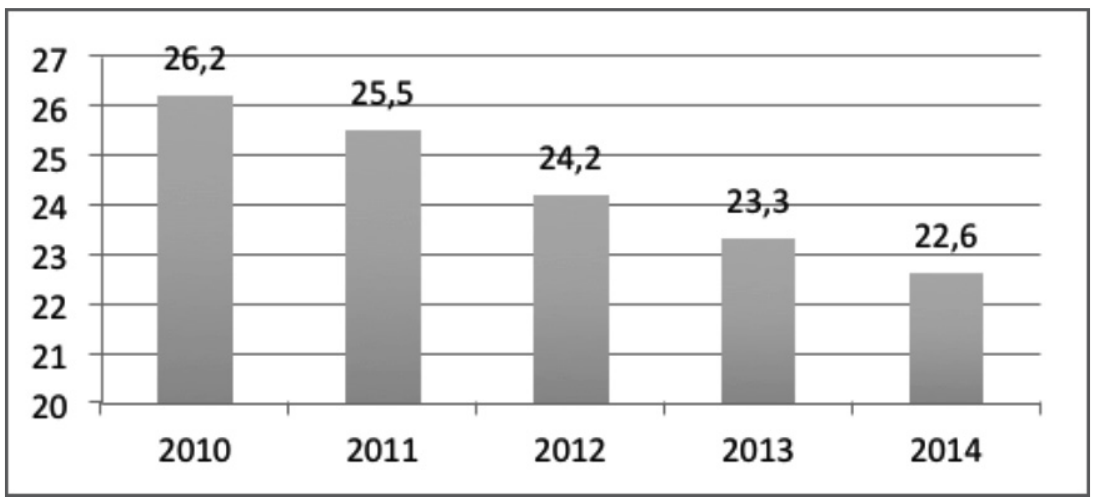

Fuente. Elaboración propia a partir de datos del Banco Mundial (2015).

Sus principales compradores son los Estados Unidos y Hong Kong, seguido de Japón y República de Corea. Exporta principalmente teléfonos -incluidos los móviles-, máquinas para procesamiento de datos, circuitos electrónicos integrados, artículos de joyería, 
dispositivos de cristal líquido, aparatos de alumbrado, monitores y proyectores, calzado, partes de vehículos, textiles y prendas de vestir, entre otros (Figura 16).

Figura 16. Principales diez países a los que exporta.

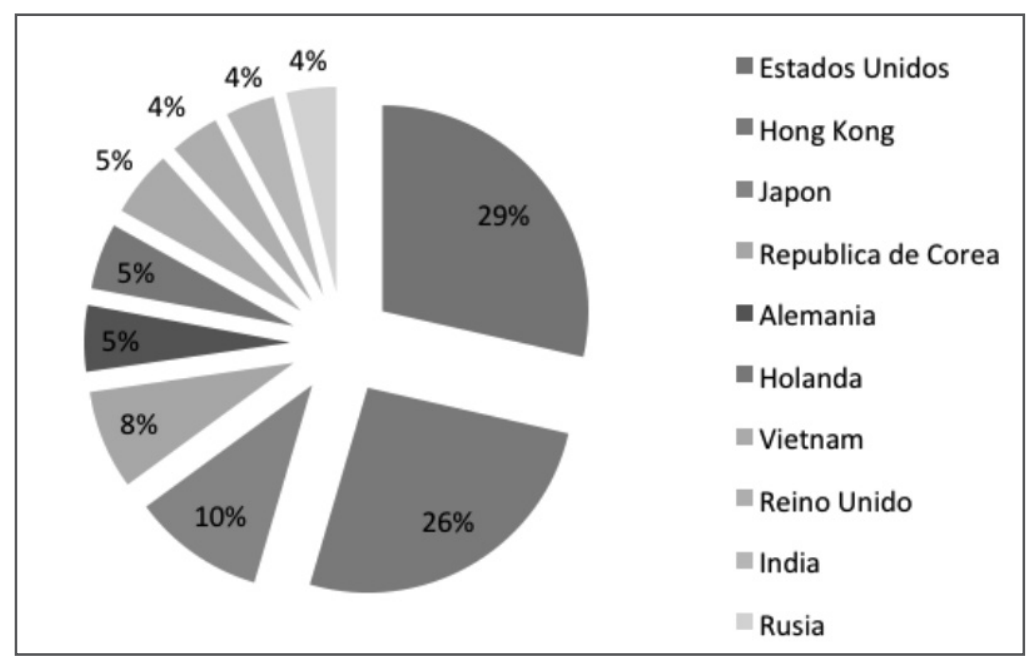

Fuente. Elaboración propia según datos de Mofcom (2015).

\subsubsection{Balanza de pagos}

China, aunque en la balanza de pagos sigue presentando un superávit importante, con relación al PIB se ha reducido drásticamente por la ralentización económica que ha tenido. Su debilidad está marcada por el zanjado déficit en la balanza de servicios donde ha aumentado el consumo en estos últimos años y no ha crecido en la exportación; sin embargo, la balanza comercial sigue siendo de admirar, lo cual deja la balanza de pagos con superávit muy por encima de la deficitaria balanza de servicios (Figura 17).

Figura 17. Saldo de cuenta corriente en millones de dólares a precios actuales.

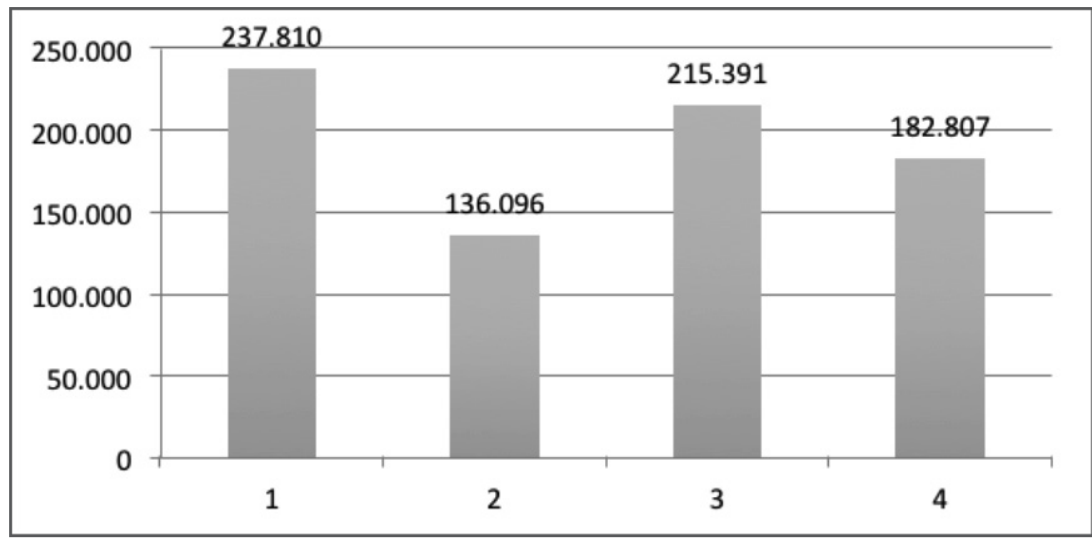

Fuente. Elaboración propia a partir de datos del Banco Mundial, (2015). 


\subsubsection{Contrabando}

China se destaca en este aspecto por tener políticas fuertes frente al contrabando, cuyo delito es severamente castigado. El contrabando de armas y dinero falso será hasta noviembre de 2015 un delito castigado con pena de muerte, cuando entre en vigencia la reforma penal y el contrabando técnico sea objeto de fuertes sanciones penales y económicas. Se presenta, sobre todo, en minerales y residuos sólidos de industria, como polvos y escorias, seguido del sector agropecuario encabezado por arroz y carne. El contrabando contribuyó a la baja en el IPC durante 2012, 2013 y 2014, sobre todo, en los precios de los alimentos por el volumen de contrabando. En China, a diferencia de Colombia, por ser fuerte en la industria textil y confección, el contrabando en este sector tiende a cero, pues, aunque recibe contrabando sobre todo de confecciones con pieles exóticas y otras, su volumen es bajo y no afecta mayoritariamente su industria, como sí lo hacen los minerales y los residuos sólidos que representan más de $80 \%$ del total (Figura 18).

Figura 18. Principales productos de contrabando.

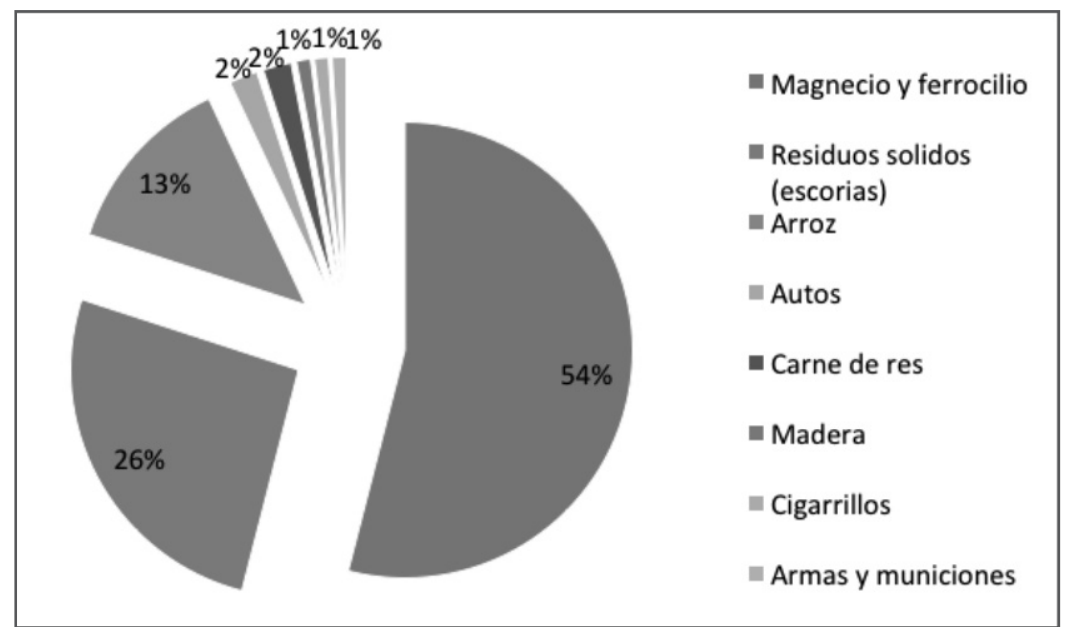

Fuente. Elaboración propia a partir de datos de la GACC, (2015).

\subsubsection{Aranceles}

China es una de las economías que más se ha protegido de las importaciones con medidas arancelarias y paraarancelarias, lo cual le ha permitido con otras economías, como Taiwán y Corea, ser altamente exportadoras y mantener superávit en su balanza de pagos.

Su ingreso en la OMC le ha exigido disminuir esta protección por presión internacional de proveedores interesados en incursionar y vender sus productos a la demanda del mercado chino; gradualmente se ha visto reducción en estas medidas que no son alentadoras. La última reducción apenas fue aprobada para entrar en vigencia en 2016 y estaba en negociación desde 2013 en la OMC y fue aprobado para 200 productos de tecnología por 54 países.

La anterior reforma está dada en junio de 2015 cuando entró en vigor la baja de tasa arancelaria para productos de consumo, que destaca trajes, pañales, zapatillas deportivas y cosméticos reduciendo en más de $50 \%$ la 
tarifa. La baja en estas tasas se da para suplir la demanda interna que no es abastecida por la producción nacional, lejana de ser una medida que busque la liberación del mercado y la libre competencia.

\subsection{Política fiscal}

\subsubsection{Impuestos}

China ha sufrido con la recaudación de impuestos tras la descentralización de la economía, sobre todo, en control fiscal, pues la variación de tasas, que depende del tamaño de las empresas, el tipo de propiedad y la participación extranjera, la evasión y las exenciones, empeora la situación.

En este quinquenio, el control fiscal y la recaudación de impuestos ha girado levemente hacia la centralización, lo cual ha permitido que las tasas se mantengan estables, a pesar de los diferentes impuestos que tiene cada provincia. Ha dado un aire de seguridad para las empresas extranjeras al no permitir variaciones bruscas y al generar un mayor control sobre los impuestos, al tiempo que se vuelve una tasa atractiva para la inversión extranjera.

En 2014, el ministro de Finanzas y el primer ministro de China informaban orgullosos a la Asamblea Popular Nacional el aumento del umbral para tributación del IVA -pasó de 2000 a 3500 RMB-, es decir que un importante número de las empresas más pequeñas dejan de tributar, además la reducción de impuesto al ingreso que benefició a 600000 PyMEs y el aumento de los estímulos fiscales para la reactivación de la economía (Figura 19).

Figura 19. Tasa tributaria.

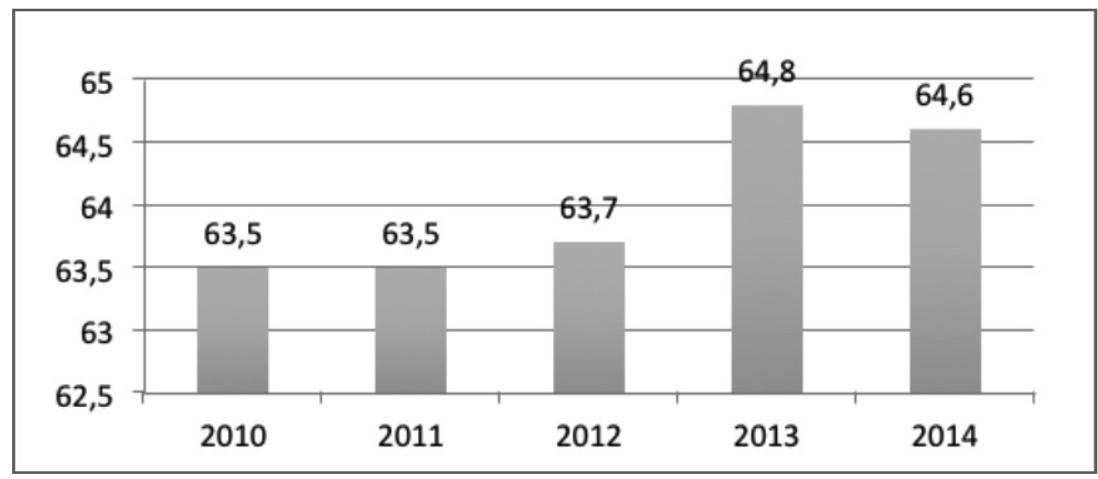

Fuente. Elaboración propia a partir de datos del Banco Mundial, (2015).

\subsection{Las políticas de competitividad en China}

En China, la competitividad siempre ha sido uno de los componentes de los planes quinquenales, que es el equivalente a los planes de desarrollo en Colombia; la diferencia es solo de forma, pues estos se diseñan para cinco años y el órgano encargado de su elaboración es el partido que gobierna.
Hay que aclarar que las recomendaciones son generales y que no existen lineamientos específicos para cada sector; sin embargo, el sector textil confección es protegido y promocionado en todos los ejes transversales, como se verá a continuación en el estudio de los últimos dos planes quinquenales. 


\subsubsection{Plan Quinquenal 2006-2010 -Partido Comunista Chino-}

Este plan denominado Programa para el Desarrollo Económico y Social Nacional tiene de novedoso que por primera vez abandona el énfasis en el crecimiento elevado (sin descuidar la exigencia de mantener un crecimiento elevado y estable) y se concentra en el desarrollo sostenible.

En lo netamente económico, este plan presenta tres grandes puntos, a saber: el primero, que si bien las recomendaciones son para mantener el orden social y más el político, por primera vez se hace expresa la voluntad de darle prioridad a la gente -yirenweibeny no a los resultados cuantitativos de producción, pensado para crear una sociedad armoniosa-hexieshehui-. Por eso, los reportes de la Organización Internacional del Trabajo (2010) sobre los salarios en China, presenta un crecimiento sostenido en el aumento salarial de 2008 a 2010, pese a la crisis económica mundial. El segundo está basado en el concepto de desarrollo científico -kexuefazhanguan- definido como la promoción de la industrialización «basándose en la demanda interna, el aumento de la productividad, el progreso técnico y científico, la reducción en el consumo de recursos y una menor contaminación» (Bustelo, 2005). Y el tercero que plantea la creación de un nuevo modelo de desarrollo pasando de extensivo a intensivo, es decir, disminuir los factores de producción y concentrarse en el crecimiento de la productividad, de estar basado en las exportaciones a tener en cuenta el mercado interno y de sustentarse en la inversión extranjera a depender de la iniciativa de los nacionales.

Este plan propone como punto aparte una alta inversión en infraestructura de transporte. Hace énfasis en el transporte terrestre con la construcción de catorce nuevas autopistas y seis nuevas vías ferroviarias, en aéreo la ampliación de diez aeropuertos, traslado y construcción de aeropuertos nacionales, y en marítimo drenaje de ríos y ampliación de puertos.

\subsubsection{Plan Quinquenal 2011-2015 -Partido Comunista Chino-}

Aunque no hay grandes cambios entre el anterior plan y este, la novedad está en la implementación del "crecimiento inclusivo" y el enmarque de China y sus desafíos sociales y económicos en el contexto global; sin embargo, puede incluso considerarse una extensión del anterior plan. Lo que respecta a los temas económicos se define en dos puntos: el primero enfocado al crecimiento basado en el consumo como eje de la transformación económica y el segundo respecto a la limitación de recursos y la degradación ambiental.

El primer punto se concentra en un plan agresivo para fomentar el consumo privado en sus 1.3 miles de millones de consumidores (Myers y Yang, 2012) para generar la transformación económica ideal para China. Para ello, concentra sus esfuerzos en el trabajo de tres herramientas: i) la urbanización, ii) el estándar de vida «razonablemente pudiente» y iii) el aumento de ingresos.

La urbanización será una herramienta para aumentar el consumo interno, por eso se plantea la cifra récord de aumentar la urbanización en 4 puntos porcentuales teniendo como meta lograr que $51.5 \%$ de la población resida en zonas urbanas para 2015 (Xinhua, citado por Myers y Yang, 2012). El estándar de vida «razonablemente pudiente» - xiaokang-se debe a la consideración de que 
«la desigualdad socavaría la credibilidad de la reforma orientada al mercado y dificultaría el desarrollo a largo plazo» (Banco Mundial, citado por Myers y Yang, 2012, p. 12). En cuanto al aumento de los ingresos, aumentaría el consumo interno con un mayor PIB per capita; el objetivo establece un aumento de al menos 13 puntos porcentuales por año (Xinhua, citado por Myers y Yang, 2012) y reformas fiscales que reduzcan los impuestos del hogar y aumenten los impuestos a las empresas.

El segundo punto propone básicamente hacer frente al cambio climático, controlar las emisiones para mejorar la calidad del aire, proteger las tierras cultivables y descontaminar ríos y lagos como medidas para hacer frente a la contaminación y los problemas de recursos de China.

Hay que destacar la gran inversión que destina este plan para avanzar en la mejora de infraestructura, sobre todo, en transporte aéreo con la construcción de 45 aeropuertos y el aumento en más de 100 $\%$ de la flota y vía terrestre la conexión por vías pavimentadas de más de $90 \%$ de las poblaciones y $30000 \mathrm{~km}$ de vías ferroviarias. Igualmente, la promoción de la innovación en alta tecnología que plantea incluso nuevas industrias emergentes estratégicas.

\section{Colombia versus China}

Ce puede inferir de qué forma los indi- cadores macroeconómicos de este tipo son el reflejo de las economías y su relación con la competitividad (Tabla 1). En el caso de China -y sin ánimo de sugerir la emulación del modelo económico chino-, es importante mencionar que el crecimiento de su PIB y de sus exportaciones se mantuvo sostenido en el tiempo; China, por más de quince años, mantuvo un crecimiento del PIB superior a $7 \%$. Esto estuvo directamente relacionado con la política de fomento a las exportaciones y el fortalecimiento del sector manufacturero para suplir la demanda internacional. Aspectos como el desempleo y la inflación han tendido a ser mucho más bajos que en Colombia, lo cual también es propio al modelo económico chino. 
Tabla 1. Principales datos de China y Colombia.

\begin{tabular}{|l|l|l|l|l|l|l|l|l|}
\hline \multirow{2}{*}{} & \multicolumn{2}{|c|}{$\mathbf{2 0 1 1}$} & \multicolumn{2}{c|}{2012} & \multicolumn{2}{c|}{2013} & \multicolumn{2}{c|}{2014} \\
\cline { 2 - 10 } & China & Colombia & China & Colombia & China & Colombia & China & Colombia \\
\hline \% crecimiento PIB & 9.5 & 6.6 & 7.8 & 4 & 7.7 & 4.9 & 7.4 & 4.6 \\
\hline Desempleo (\%) & 4.3 & 11.1 & 4.5 & 10.6 & 4.6 & 10.5 & 4.09 & 9.1 \\
\hline Tasa de interés real & -1.5 & 4.2 & 3.5 & 9.3 & 3.7 & 8.9 & 4.7 & 8.9 \\
\hline Inflación & 5.4 & 3.4 & 2.7 & 3.2 & 2.6 & 2 & 2 & 2.9 \\
\hline $\begin{array}{l}\text { Importaciones } \\
\text { (\% PIB) }\end{array}$ & 23.4 & 19.9 & 21.5 & 20 & 20.6 & 20.2 & 18.9 & 21.5 \\
\hline $\begin{array}{l}\text { Exportaciones } \\
\text { (\% PIB) }\end{array}$ & 25.5 & 18.7 & 21.2 & 18.3 & 23.3 & 17.6 & 22.6 & 16 \\
\hline $\begin{array}{l}\text { Saldo cuenta } \\
\text { corriente (millones } \\
\text { de dólares precios } \\
\text { actuales) }\end{array}$ & 136096 & -9710 & 215391 & -11305 & 182807 & -12330 & & -19789 \\
\hline Tasa tributaria & 63.5 & 76.4 & 63.7 & 76 & 64.8 & 76.1 & 64.6 & 77.3 \\
\hline
\end{tabular}

Fuente. Elaboración propia a partir de datos del Banco Mundial, (2015) y Cepal, (2014).

\section{Conclusiones}

$\triangle$ pesar de la crisis mundial actual y de la desaceleración en los dos últimos años del crecimiento chino, es relevante mencionar que su economía es la segunda más fuerte del mundo después de la de los Estados Unidos; son los mayores exportadores de manufacturas del mundo y en especial, a lo que interesa a esta investigación, son los principales exportadores de textiles y confecciones en el mundo; siendo capaces de vender a precios sumamente bajos, con la calidad que se les requiera y con los estándares que demande la economía mundial. Así pues, la política económica sí va atada a la competitividad de los países, porque es en el diseño de ella donde se trazan los derroteros de hacia dónde quiere ir el país y a cuáles sectores productivos se van a jalonar a través de ella.

Colombia, acostumbrada a la exportación de commoditiesy a las relaciones comerciales con las economías que los demanden, encontró en China un socio comercial que después de 2011 se posicionó como el tercer destino de las exportaciones y el segundo proveedor de sus importaciones, que distante de la política de diversificación de mercados para sus exportaciones sigue concentrando como destino un grupo pequeño de países, que si bien significan un mercado amplio, significa también mayor dependencia y sensibilidad ante factores externos que pueden desencadenar en resultados no deseados para la economía nacional.

La economía de China explicada por los ciclos de Kondratiev, está en la actualidad en la etapa inicial de su desaceleración larga, tan larga como fue su periodo de crecimiento. La ralentización en esta economía afectará y ya se empieza a sentir, por ejemplo en la baja de las exportaciones, que si bien tiene otros ingredientes, también está 
representada por la menor demanda de la industria china de insumos y materias primas para la producción.

Colombia debe tomar atajos en procesos y factores para fortalecer su economía y más específicamente el sector de confección, no necesariamente la protección del mercado como en el caso chino, porque en los años de cierre no tuvo resultados envidiables. Pero sí puede, por ejemplo, reducir sus tasas tributarias para equiparar la rentabilidad al menos en este aspecto al de los países como China, la India y México, competencia de primera en el sector confección. Asi mismo, debe combatir el contrabando con aumento en los controles a importaciones, para lo que requiere de mayor inversión en recursos humanos que permita hacer los controles efectivos.

La conclusión recurrente a la que se llegaba para explicar por qué China invadió diferentes mercados con sus productos a bajos precios citando la mano de obra barata empieza a quedarse sin argumentos, pues China, a partir de 2008, por orden del Gobierno central, y luego, en 2011, consignado como principio en el Plan Quinquenal, inició un régimen de aumento sostenido en los salarios, con el fin de incrementar el consumo interno y avanzar hacia la construcción de una hexieshehui -sociedad armoniosa- que está pensado en la gente -yirenweiben-. Aunque son recomendaciones del Partido Comunista para mantener el orden social y político, también reflejan el sentir de cientos de ciudadanos que protestaron en las principales ciudades chinas, pero que más que eso, es una jugada a tres bandas. Por un lado, escuchan el clamor de sus conciudadanos, se quitan las miradas de los organismos internacionales que acusaban al Gobierno de condiciones laborales no favorables; y por otro, incentivan el consumo nacional, ya que una de las recomendaciones del Partido Comunista fue girar hacia esa política, pues los mercados externos le generan bastante volatilidad a la economía. En esto, Colombia no tiene excusa, pues, aunque todos los años los empresarios se han quejado de volver la economía menos competitiva con las altas tasas de incremento salarial, China ha dado un paso en la construcción de una economía sostenible, con mucho todavía por mejorar.

Lejos está Colombia de lograr un crecimiento sostenido en la economía al punto que permita entrar en la clasificación de grupos desarrollados; igual de lejos está China de volver a la senda del crecimiento al punto anterior, pues no hay buenos augurios, al menos para la segunda que ha intentado por diferentes políticas volver a la tasa de crecimiento, pero parece que es en vano. Colombia tiene potencial para aumentar la tasa de crecimiento aplicando políticas en plan de exportaciones que diversifiquen productos y mercados, un plan que incentive las exportaciones, y en temas tributarios ajustándolos a valores razonables, volviendo más sencilla la declaración de impuestos y aumentando los controles a la evasión.

Este estudio es un primer paso para la ejecución del proyecto, ya que, para la revisión con enfoque sistémico, se necesita concretar el trabajo de campo, la muestra sectorial necesaria que permita arrojar resultados en el ámbito académico y empresarial. Alternar variables y elementos tan complejos gesta posiciones e interpretaciones diferentes, pero reafirma la necesidad de trabajar en el progreso de las PyMEs como actores sociales, políticos y económicos fundamentales para el progreso y desarrollo del país. 


\section{Referencias}

Banco de la República. (2010-2014). Informe del comportamiento de la balanza de pagos de Colombia. Bogotá, Colombia. Recuperado de http://www.banrep. gov.co/es/informe-comportamientobalanza-pagos-colombia?field date_format_value[value]=\&feed_ me $=$ \&destination $=$ informecomportamiento-balanza-pagos

Banco de la Republica, S. (2015). Política económica. Recuperado de http:/ /www.banrepcultural. org/blaavirtual/ ayudadetareas/economia/politica_ economica

Banco Mundial (2015). Indicadores. Recuperado de http://datos.bancomundial. org/indicador

Bustelo, P. (2005). China 2006-2010: ¿'hacia una nueva pauta de desarrollo? Boletín Elcano, 75. Recuperado de http:// biblioteca.ribei.org/855/1/ARI-1272005-E.pdf
Cepal (Comisión Económica para América Latina y el Caribe) (2014). Balance preliminar de las economías de América Latina y el Caribe. Recuperado de http:// www.cepal.org/es/publicaciones/37344balance-preliminar-economias-americalatina-caribe-2014

David, F. (2003). Conceptos de Administración Estratégica. México, D.F., México: Pearson Educación.

DIAN (Dirección de Impuestos y Aduanas Nacionales) (s. f.). Proyecto de Ley 94 de 2013, Ley Anticontrabando. Recuperado de http://www.dian.gov.co/descargas/ normatividad/2014/Proyectos/Proyecto_ de_Ley_Anticontrabando.pdf

DIAN (Dirección de Impuestos y Aduanas Nacionales) (2015). Rendición de cuentas. Recuperado de http://www.dian.gov.co/ dian/14cifrasgestion.nsf/pages/Redicion_ de_cuentas?opendocument

Díaz-Granados, S. (2011). III Foro Nacional de Importadores. Recuperado de http://www.mincit.gov.co/loader. 